\title{
How burning money requires a lot of rationality to be effective
}

Citation for published version (APA):

Seel, C., \& Wichardt, P. (2012). How burning money requires a lot of rationality to be effective. Economics Letters, 115(1), 111-113. https://doi.org/10.1016/j.econlet.2011.11.044

Document status and date:

Published: 01/04/2012

DOI:

10.1016/j.econlet.2011.11.044

Document Version:

Publisher's PDF, also known as Version of record

Document license:

Taverne

Please check the document version of this publication:

- A submitted manuscript is the version of the article upon submission and before peer-review. There can be important differences between the submitted version and the official published version of record.

People interested in the research are advised to contact the author for the final version of the publication, or visit the DOI to the publisher's website.

- The final author version and the galley proof are versions of the publication after peer review.

- The final published version features the final layout of the paper including the volume, issue and page numbers.

Link to publication

\footnotetext{
General rights rights.

- You may freely distribute the URL identifying the publication in the public portal. please follow below link for the End User Agreement:

www.umlib.nl/taverne-license

Take down policy

If you believe that this document breaches copyright please contact us at:

repository@maastrichtuniversity.nl

providing details and we will investigate your claim.
}

Copyright and moral rights for the publications made accessible in the public portal are retained by the authors and/or other copyright owners and it is a condition of accessing publications that users recognise and abide by the legal requirements associated with these

- Users may download and print one copy of any publication from the public portal for the purpose of private study or research.

- You may not further distribute the material or use it for any profit-making activity or commercial gain

If the publication is distributed under the terms of Article $25 \mathrm{fa}$ of the Dutch Copyright Act, indicated by the "Taverne" license above, 


\title{
How burning money requires a lot of rationality to be effective
}

\author{
Christian Seel ${ }^{\mathrm{a}, *}$, Philipp C. Wichardt ${ }^{\mathrm{b}, \mathrm{c}}$ \\ ${ }^{a}$ Hausdorff Center for Mathematics, Institute for Economics and Social Sciences, University of Bonn, Lennéstr.43, D-53113 Bonn, Germany \\ ${ }^{\mathrm{b}}$ Economic Theory 3, Department of Economics, University of Bonn, Germany \\ ${ }^{\mathrm{c}}$ Department of Economics, Ludwig-Maximilian-University Munich, Germany
}

\section{A R T I C L E I N F O}

\section{Article history:}

Received 2 May 2011

Received in revised form

2 November 2011

Accepted 30 November 2011

Available online 13 December 2011

\section{JEL classification:}

C72

Keywords:

Bounded rationality

Burning money

Forward induction

Valuation equilibrium

\section{A B S T R A C T}

This paper proposes an extension of the valuation equilibrium concept (Jehiel and Samet, 2007), which partly endogenises the underlying grouping of actions. The effect on equilibrium predictions is illustrated in a burning money game.

(C) 2011 Elsevier B.V. All rights reserved.

\section{Introduction}

An interesting recent approach to model bounded rationality is the valuation equilibrium concept presented by Jehiel and Samet (2007). The idea of the concept is that the (boundedly rational) players of a game, instead of considering all moves separately, bunch "similar" moves into groups and attach a valuation to every group of similar actions. In equilibrium, each player then chooses actions with locally maximal valuations, where "locally" refers to the decision node, and valuations are confirmed by equilibrium outcomes.

In the present paper, we take up the discussion of the valuation equilibrium concept and ask how far the grouping of actions, which is an essential constituent of the concept, effects the equilibrium analysis of simple extensive form games. Extending the earlier argument, however, we do not treat the grouping of a player as entirely exogenous. Instead, we start with an intuitive basic grouping which players can refine, but only at a small cost. A valuation equilibrium then is said to be robust, if no player has an incentive to change his partition of moves or his strategy, given the strategies of the others. Thus, the refined equilibrium concept takes

\footnotetext{
* Corresponding author. Tel.: +49 228734660 .

E-mail addresses: cseel@uni-bonn.de (C. Seel),philipp.wichardt@uni-bonn.de (P.C. Wichardt).
}

into account the trade-off between the cost of a more complex grouping and the potential benefit it may induce.

In order to illustrate the virtues of the modified definition, we finally compare its predictions with traditional predictions for the burning money game initially proposed by Ben-Porath and Dekel (1992). ${ }^{1}$ The comparison emphasises how the first mover advantage, which is usually ascribed to player 1 in this game using a forward induction argument, relies on player 2 fully exploiting all available information. In particular, if differentiating moves is costly for player 2, money is never burned in equilibrium and all equilibria of the one-shot coordination game are possible in the second stage. Hence, the modified valuation concept predicts that the mere possibility to burn money does not affect the outcome of the coordination game. In fact, this is roughly in line with the empirical evidence gathered by Huck and Müller (2005), which supports only a comparably small first mover advantage (the observed frequency of the preferred outcome for player 1 is far lower than predicted by the forward induction argument). ${ }^{2}$

\footnotetext{
1 The burning money game combines a common coordination game with a first stage in which player 1 has the opportunity to "burn money", i.e. choose a strategy which reduces his payoff. Using a forward induction argument, Ben-Porath and Dekel (1992) show that the mere possibility to burn money (which is not played in equilibrium) allows player 1 to induce player 2 to coordinate on player 1's most preferred outcome.

2 Note that it seems plausible to assume that there are always some people who behave more rationally (or clever) than others, e.g. due to their experience with similar but differently incentivised interactions.
} 


\section{The model}

Part 1 of this section briefly reviews the definition of the sequential valuation equilibrium concept by Jehiel and Samet (2007). Part 2 introduces the notion of a robust valuation equilibrium.

\subsection{The basic setup of Jehiel and Samet (2007)}

Following Jehiel and Samet (2007), we consider finite extensiveform games, where $\ell$ is the finite set of players $i=1, \ldots, I, Z$ is the finite set of terminal nodes, and $\mathcal{N}$ is the finite set of non-terminal nodes. The payoff of each player at each terminal node is specified by a function $f_{i}: Z \rightarrow \mathbb{R}$. Player's use behavioural strategies $\sigma_{i}$, which specify a probability distribution over actions for each node, at which the player has to move. The probability distribution over terminal nodes induced by the player's strategies is denoted $P^{\sigma}$. Moreover, the set of moves $M_{i}$ is partitioned into similarity classes $\lambda_{i} \in \Lambda_{i}$. And each player attaches a valuation $v_{i}: \Lambda_{i} \rightarrow \mathbb{R}$ to each similarity class.

In a sequential valuation equilibrium, the players strategies have to be optimal given valuations and valuations have to be sequentially consistent with the strategies. Roughly speaking, consistency requires that the valuation of a similarity class equals the expected payoff (given all players' strategies) a player obtains conditional on having actually used a move from the respective class. More formally, a valuation $v_{i}$ is consistent with a strategy profile $\sigma$ if, for all $\lambda \in \Lambda_{i}$ with $P^{\sigma}(Z(\lambda))>0$,

$\nu_{i}(\lambda)=E^{\sigma}\left(f_{i} \mid Z(\lambda)\right)=\sum_{z \in Z(\lambda)} \frac{P^{\sigma}(z) f_{i}(z)}{P^{\sigma} Z(\lambda)}$.

$v_{i}$ is sequentially consistent, if there is a fully mixed sequence $\left(\sigma^{k}\right)_{k=1}^{\infty}$ such that $\sigma^{k} \rightarrow \sigma$ and $v_{i}^{k} \rightarrow v_{i}$, where $v_{i}^{k}$ is the unique consistent valuation for $\sigma^{k}$.

Moreover, a strategy $\sigma_{i}$ is optimal given $v_{i}$, if according to $\sigma_{i}$ player $i$ at each decision node chooses an action from a similarity class with the (locally) highest valuation.

As in Wichardt (2011), we henceforth restrict the set of admissible strategies to those which use the same probability distribution whenever the set of optimal actions is identical. We refer to this as uniform tie-breaking. ${ }^{3}$

For a more extensive introduction and additional intuition about the basic setup, see Jehiel and Samet (2007) or Wichardt (2011).

\subsection{Restricting the partitions}

To make the concept applicable to a game without having to specify a partition entirely ad hoc, we restrict the set of partitions in two ways. First, we define a primary partition of moves which is supposed to capture a priori similarity of actions; for the present purposes we assume that a priori similarity is reflected in the labelling of actions.

Definition 1. In the primary partition $\Lambda_{i}^{0}$ of player $i$, two moves are in the similarity class if and only if they have the same label.

Moreover, we define a preordering on the remaining partitions.

Definition 2. A partition $\Lambda_{i}$ is (weakly) finer than $\Lambda_{i}^{\prime}$, if $\Lambda_{i}$ contains at least as many similarity classes as $\Lambda_{i}^{\prime}$. Otherwise it is coarser than $\Lambda_{i}^{\prime}$.

Intuitively, a more complex partition requires closer attention to the game, which is more "costly" in terms of memory. And the

\footnotetext{
3 See Wichardt (2011) for a formal definition of the uniform tie-breaking
} condition.

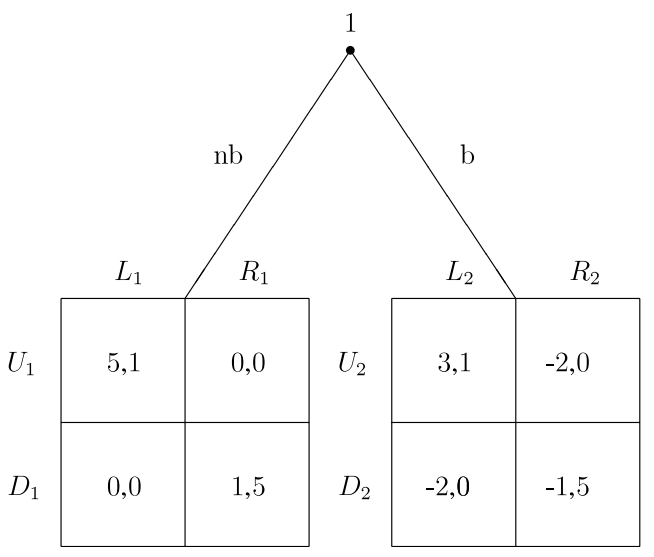

Fig. 1. The burning money game; in stage 2, player 1 chooses rows and player 2 chooses columns.

preordering of similarity classes offers a measure for complexity of the partition which we can integrate into the equilibrium concept ${ }^{4}$ :

Definition 3. A profile $(\sigma, v, \Lambda)$ is a robust valuation equilibrium (RVE) if for all $i$

1. $v_{i}$ is sequentially consistent with $\sigma$,

2. $\sigma_{i}$ is optimal given $v_{i}$ and satisfies uniform tie-breaking,

3. for any coarser partition $\Lambda_{i}^{\prime}$ and all pairs $\left(\sigma_{i}^{\prime}, v_{i}^{\prime}\right)$ allowed by $\Lambda_{i}^{\prime}$ such that $\sigma_{i}^{\prime}$ is optimal given $v_{i}^{\prime}$ and $v_{i}^{\prime}$ is sequentially consistent with $\left(\sigma_{i}^{\prime}, \sigma_{-i}\right)$, we have $u_{i}\left(\sigma_{i}^{\prime}, \sigma_{-i}\right)<u_{i}(\sigma)$,

4. for any (weakly) finer partition $\Lambda_{i}^{\prime \prime}$ and all pairs $\left(\sigma_{i}^{\prime \prime}, v_{i}^{\prime \prime}\right)$ allowed by $\Lambda_{i}^{\prime \prime}$ such that $\sigma_{i}^{\prime \prime}$ is optimal given $v_{i}^{\prime \prime}$ and $v_{i}^{\prime \prime}$ is sequentially consistent with $\left(\sigma_{i}^{\prime \prime}, \sigma_{-i}\right)$ we have $u_{i}\left(\sigma_{i}^{\prime \prime}, \sigma_{-i}\right) \leq$ $u_{i}(\sigma)$.

\section{The burning money game}

Finally, we discuss an application of the robust valuation equilibrium concept to the burning money game introduced by Ben-Porath and Dekel (1992). In this 2-stage, 2-player game, player 1 first decides whether to play $b$ ("burn money") or $n b$ ("not burn money"), where $b$ reduces the payoff of player 1 in stage 2 , but has no effect otherwise. The second stage is a coordination game, where player 1 can choose between $U$ and $D$ and player 2 can choose $L$ or $R$. The payoffs are specified in Fig. 1, where subindices are added only for notational convenience.

Intuitively, it is not clear why the mere additional possibility to "burn money," i.e. publicly harm oneself, should have an influence on the equilibrium set. Yet, for standard equilibrium concepts such as subgame perfect equilibrium or forward induction arguments, the additional option of "burning money" does matter.

In order to select among the subgame perfect equilibria for this game, Ben-Porath and Dekel (1992) propose to use the following forward induction argument ${ }^{5}$ : Given player 1 played $b$, he must hold the belief that player 2 plays $\sigma_{2}=\left(R_{1}, L_{2}\right)$, as otherwise $b$ is strictly dominated by $n b$. Observing $b$, player 2 infers the belief of player 1 and accordingly plays $L_{2}$ which guarantees a payoff of 3 to player 1 . However, if player 2 observes $n b$ although player 1 can guarantee himself a payoff of 3 by playing $b$, then, the

\footnotetext{
4 Note that the modified concept is equivalent to the introduction of a lexicographic cost for choosing a finer partition (the results in this paper also hold for a small, but fixed cost $c$ for a finer partition). Moreover, the idea of lexicographic preferences favouring the choice of simpler strategies as expressed in the definition is similar to the lexicographic preference for simpler (finite) automata suggested by Rubinstein (1986).

5 Forward induction was introduced by Van Damme (1989).
} 
argument goes, player 2 ought to infer that player 1 expects player 2 chooses $L_{1}$ after $n b$ which should be answered by $U_{1}$. Thus, the mere possibility to burn money induces the equilibrium outcome (b; $U_{1} U_{2}, L_{1} L_{2}$ ) which is most preferred by player 1 .

Although undoubtedly appealing from a theoretical perspective, the forward induction argument is intuitively quite involved. And, in fact, the bounded rationality concept proposed here does not yield the same predictions. In particular, in any RVE, money is (also) never burned, but equilibrium play in the second stage can be any equilibrium of the one-shot coordination game.

Proposition 1. In any RVE, each player uses his primary partition $\Lambda_{i}^{0}$, where $\Lambda_{1}^{0}=\left\{n b, b, U=\left\{U_{1}, U_{2}\right\}, D=\left\{D_{1}, D_{2}\right\}\right\}$ and $\Lambda_{2}^{0}=\{L=$ $\left.\left\{L_{1}, L_{2}\right\}, R=\left\{R_{1}, R_{2}\right\}\right\}$ and equilibrium strategies are given by

(i) player 1 choosing $n b$ and $U_{1} U_{2}$, player 2 choosing $L_{1} L_{2}$,

(ii) player 1 choosing $n b$ and $D_{1} D_{2}$, player 2 choosing $R_{1} R_{2}$,

(iii) player 1 choosing $n b$ and $\frac{5}{6} U_{1}+\frac{1}{6} D_{1} ; \frac{5}{6} U_{2}+\frac{1}{6} D_{2}$, player 2 choosing $\frac{1}{6} L_{1}+\frac{5}{6} R_{1} ; \frac{1}{6} L_{2}+\frac{5}{6} R_{2}$.

Proof. The structure of the proof is as follows: first, we show that there are no RVE in which any player uses a refined partition; in a second step, we then establish that the only RVE for the primary partitions are those given in the proposition.

1. To begin with, note that in any equilibrium in which player 1 does not randomise at stage 1 , one branch of the tree is never followed. Hence, both players can ensure themselves whatever payoff they can get using the (cheaper) coarsest primary partition $\Lambda_{i}^{0}$. Consequently, in any RVE, for a player to use a partition finer than $\Lambda_{i}^{0}$, player 1 has to randomise at the first stage. Player 1 randomising at stage, however, requires $v_{1}(b)=v_{1}(n b)$. Moreover, the equilibrium condition implies that both players have to play mutual best responses after $b$ and $n b$ in the second stage. Yet, for any two equilibria in the one-shot game after $b$ and $n b$, the payoffs of player 1 differ, irrespective of player 1's partition, depending on whether $n b$ or $b$ was played in stage $1 .^{6}$ Thus, player 1 's valuations for $b$ and $n b$ have to differ (contrary to what was assumed). Accordingly, there are no equilibria in which a player uses a refined partition.

2. Next, consider the case in which both players use their primary partition $\Lambda_{i}^{0}$. In this case, no player can condition his equilibrium behaviour on the first move of player 1 ; this is an immediate consequence of the uniform tie-breaking condition (cf. Wichardt, 2011) in conjunction with the primary partitions $\Lambda_{i}^{0}, i=1,2$. Moreover, given that player 2's equilibrium behaviour at the second stage is independent of whether $b$ or $n b$ was played in stage 1 , it never pays for player 1 to play $b$. And this, in turn, implies that no player has an incentive to opt for a finer partition.
Finally, by sequential consistency, mutual best responses are played on the equilibrium path at the second stage. Hence, (i)-(iii) are the only candidates for an RVE for the coarsest partitions $\Lambda_{i}^{0}$, since off-equilibrium path (after $b$ is played) both players follow the same local behaviour as on the equilibrium path by the uniform tie-breaking condition. Moreover, as already argued in the first part of the proof, without player 1 randomising (as is the case in the candidate equilibria), no player benefits from switching to a finer partition, which would allow a more differentiated behaviour; i.e. both players already obtain the highest possible payoff using their primary partition in (i)-(iii). Therefore, these strategy-partition combinations are robust to finer partitioning and robust to coarser partitioning. Hence, they are RVE.

As we have already shown that there are no equilibria in which any player uses a finer partition, this completes the proof.

Intuitively, "burning money" does not have an effect simply because player 2 would have to invest into a finer partitioning in order to take it into account-and of course the game does not induce any incentive for him to do so. In that sense, the robust valuation equilibrium concept highlights the comparably high degree of rationality implicitly ascribed to player 2 in common forward induction arguments.

In fact, Huck and Müller (2005) tested the predictions of the burning money game in an experiment. In a repeated version of the game, they find that, while money is rarely burned (about 6\% of the games), the observed frequency of the preferred outcome of player 1 is far lower than predicted by the forward induction argument-a result which is roughly in line with the predictions of the robust valuation equilibrium concept. ${ }^{7}$

\section{Acknowledgements}

We are grateful to Philippe Jehiel, Avner Shaked, Tymon Tatur, Matthias Lang and an anonymous reviewer for helpful comments and discussions.

\section{References}

Ben-Porath, E., Dekel, E., 1992. Signaling future actions and the potential for sacrifice. Journal of Economic Theory 57, 36-51.

Huck, S., Müller, W., 2005. Burning money and (pseudo) first-mover advantages: an experimental study on forward induction. Games and Economic Behavior 51, 109-127.

Jehiel, P., Samet, D., 2007. Valuation equilibrium. Theoretical Economics 2, 163-185. Rubinstein, A., 1986. Finite automata play the repeated Prisoner's Dilemma. Journal of Economic Theory 39, 83-96.

Van Damme, E., 1989. Stable equilibria and forward induction. Journal of Economic Theory 48, 476-496.

Wichardt, P., 2011. Existence of valuation equilibria when equilibrium strategies cannot differentiate between equal ties. Games and Economic Behavior doi:10.1016/j.geb.2011.08.009.

\footnotetext{
6 Possible equilibrium payoffs for player 1 are: 5,1 or $5 / 6$ (mixed) after $n b$, and $3,-1$ or $-7 / 6$ (mixed) after $b$.
}

\footnotetext{
7 Exact frequencies in Huck and Müller (2005) vary depending on the exact assignment of the game.
} 